Brazilian Journal

of Chemical

ISSN 0104-6632

Printed in Brazil

Engineering

www.scielo.br/bjce

Vol. 35, No. 02, pp. 415 - 428, April - June, 2018

dx.doi.org/10.1590/0104-6632.20180352s20160175

(cc) BY

\title{
LIQUID-LIQUID EQUILIBRIUM AND KINETICS OF ETHANOLIC EXTRACTION OF SOYBEAN OIL USING ETHYL ACETATE AS CO-SOLVENT
}

\author{
João L. A. Dagostin ${ }^{1}$, Danielle Carpiné1, Paulo R. S. dos Santos ${ }^{1}$, \\ Marcos L. Corazza ${ }^{1, *}$ \\ ${ }^{1}$ Department of Chemical Engineering, Federal University of Paraná - P.O. Box 19011, \\ Curitiba, Paraná - CEP: 81531-990 - Brazil.
}

(Submitted: March 14, 2016; Revised: April 17, 2017; Accepted: May 17, 2017)

\begin{abstract}
This work reports a new set of experimental data for the liquid-liquid equilibrium (LLE) of the system (soybean oil + ethyl acetate + anhydrous ethanol) and the kinetics of crude oil extraction from soybean flakes using anhydrous ethanol + ethyl acetate mixtures. Data for the LLE binodal were measured at 298.15, 313.15 and $333.15 \mathrm{~K}$ by the cloud point method and tie-lines were obtained at 298.15 and $313.15 \mathrm{~K}$. LLE data were successfully modeled using the NRTL model. Batch extractions were performed at 298.15, 313.15 and $328.15 \mathrm{~K}$ at a fixed $(4: 1)$ solvent to soybean flake mass ratio and two concentration of ethyl acetate $(5 \%$ and $10 \%$ ) in ethanol. Higher temperatures increased the solubility of the system and improved the extraction yields. In addition, higher ethyl acetate ratios in anhydrous ethanol led to an increase in the total amount of crude oil extracted when operating at 298.15 and $313.15 \mathrm{~K}$. At $328.15 \mathrm{~K}$, no improvement in extractions was verified when $5 \%$ and $10 \%$ of ethyl acetate were used in the ethanol. A mass transfer model based on Fick's Law was applied to describe the extraction kinetics, presenting an average relative deviation of $\pm 5.11 \%$, in terms of extraction yield.
\end{abstract}

Keywords: Liquid-liquid equilibrium, extraction, kinetics, soybean oil, ethanol.

\section{INTRODUCTION}

Production of vegetable oils is an important sector of agribusiness. This product is supplied to several areas of processing, transformation and consumption, such as chemical plants, steelmaking, and the food and feed industries. Soybean is the second largest oil source in the world, and Brazil stands as the second largest producer worldwide (USDA, 2017).

Soybean oil extraction is a well-established process, based on dragging oil and nonpolar components by a solvent, followed by subsequent steps of purification and refining. Predominantly, the solvent used in soybean oil extraction is commercial hexane, a mixture of petroleum hydrocarbons. The versatility of this solvent lies in its high oil solubilizing efficiency and low boiling point, ranging from 338 to $342 \mathrm{~K}$ $\left(65\right.$ to $\left.69^{\circ} \mathrm{C}\right)$, which facilitates its recovery (Kemper, 2005). However, hexane is toxic if determined concentrations are ingested or inhaled. The compound present at highest amounts in commercial hexane is $n$ -hexane, a highly flammable component that presents autoignition at $498 \mathrm{~K}\left(225^{\circ} \mathrm{C}\right)$. Furthermore, due to its high volatility, it can form explosive mixtures with air in the range of 1.1 to $7.5 \%$ (vol.) (NRC, 1995). According to US health agencies, the daily limit of

* Corresponding author: Dr. Marcos L. Corazza, Department of Chemical Engineering, Federal University of Paraná, PO Box 19011 Polytechnic Center, Curitiba 81531-980, PR, Brazil. Email: corazza@ufpr.br; Tel.: +55-41-33613190.

This is an extended version of the manuscript presented at the VIII Brazilian Congress of Applied Thermodynamics - CBTermo 2015, Aracaju, Brazil. 
exposure allowed for this component is $500 \mathrm{ppm}$ (OSHA, 2017), and the maximum limit recommended is $50 \mathrm{ppm}$ (NIOSH, 2017). In Brazil there are no regulations set for this specific type of solvent.

Several alternative solvents have been proposed in substitution to hexane in oil-seed extractions, such as trichloroethylene, $n$-heptane, ethanol, isopropanol and propanol (Gandhi et al., 2003; Seth et al., 2007; Thomas, 2003), besides the use of other techniques such as supercritical fluid extraction (de Melo et al., 2014; dos Santos Freitas et al., 2008; Eggers et al., 1985; Koubaa et al., 2016; Rai et al., 2016; Stahl et al., 1980), compressed fluid extraction (Coelho et al., 2016; dos Santos Freitas et al., 2008; Pederssetti et al., 2011), microwave and ultrasound-assisted extraction (Adam et al., 2012; Araujo et al., 2013; Cravotto et al., 2008; Hu et al., 2012; Lee et al., 2012; Uquiche et al., 2008). Among the alternative replacements for hexane, ethanol seems to be a promising solvent for Brazilian industries, since the country is a pioneer in the technological development and production of ethanol from sugarcane, making its cost relatively low when compared to those obtained from other sources, such as corn or sugar beet (Baümler et al., 2016; Gandhi et al., 2003; Seth et al., 2007; Toda et al., 2016). In addition, ethanol presents lower health risks and flammability than hexane and its isomers. However, the oil solubilization in ethanol is lower (partial) than in hexane (completely miscible), what causes a reduction in extraction efficiency (Baümler et al., 2016; Gandhi et al., 2003; Seth et al., 2007).

It is very common to use co-solvent phase equilibrium studies to evaluate the performance of components solubility. For this purpose, the co-solvent should be soluble in both solvent and solute. Thus, using a co-solvent in the soybean crude oil extraction with ethanol as solvent could be a viable alternative to the process.

In a previous study, the solubility of soybean oil in ethanol was improved by using biodiesel as co-solvent (Dagostin et al., 2015a). Biodiesel is a renewable fuel produced from oil and/or fatty acids and an alcohol through appropriate processes. It comprises a mixture of monoalkyl esters of varied composition according to the fatty raw material used as substrate. Due to the fatty material nature (long chain fatty acids), biodiesel esters present high molecular weight, which directly influences the boiling point of each component and also the whole mixture towards higher temperatures. This characteristic of biodiesel makes its recovery from oil unfeasible if regular extraction processes are used. Following the results obtained in the previous work (Dagostin et al., 2015a), the use of a single, recoverable, and adequate low boiling point ester in the ethanolic extraction of vegetable oils is a promising strategy for future purification processes.

Ethyl acetate is an oxygenated organic solvent, frequently used in chromatographic techniques and in chemical, cosmetic and food industries. This chemical presents a relatively low-boiling point $(\sim 350 \mathrm{~K})$, is a renewable and low toxicity component, and is completely miscible with ethanol. Also, the use of ethanol + ethyl acetate mixtures (instead of pure ethyl acetate) is justified mostly due to the lower price of ethanol, which can be more evident in areas where the alcohol is produced from sugarcane, as in Brazil for instance. The synthesis of ethyl acetate can occur through different pathways, such as a Fischer esterification of ethanol with acetic acid, the addition of acetic acid to ethylene, a Tishchenko reaction involving two acetaldehydes, and the dehydrogenate dimerization of ethanol (Inui et al., 2002; Nielsen et al., 2012). The first and last methods may represent interesting alternatives for industries already working with ethanol as feedstock, since ethyl acetate could be produced at the same plant.

Taking into account these characteristics, using ethyl acetate as a co-solvent in the ethanolic extraction of soybean oil emerges as a promising possibility. Furthermore, this solvent mixture (ethanol+ethyl acetate) could be completely removed by distillation, allowing separation in conventional extraction plants. In this context, this work aims to evaluate solubility, in terms of liquid-liquid equilibrium information, for the ternary system involving soybean oil (solute) + ethyl acetate (co-solvent) + ethanol (solvent) and also to investigate the kinetics of ethanolic extraction of soybean crude oil using ethyl acetate as co-solvent.

\section{MATERIALS AND METHODS}

\section{Materials}

Absolute ethanol ( $>99.8 \%$ vol, Panreac, Spain), ethyl acetate ( $99.5 \mathrm{wt} \%$, F.Maia, Brazil) were used in both the liquid-liquid equilibrium (LLE) measurements and soybean crude oil extraction. Refined soybean oil (LIZA, Brazil) was used in the LLE experiments. The fatty acids composition of this soybean oil is described elsewhere (Dagostin et al., 2015a). Soybean flakes (Glycine max) provided by IMCOPA (Brazil) were used in the extraction procedures. The 
soybean flakes were stored $\left(-12^{\circ} \mathrm{C}\right)$ in vacuum-sealed polyethylene bags when received, which were opened prior to the extractions. All chemicals were used without further purification.

\section{Determination of solubility curves and liquid-liquid equilibrium data (tie-lines)}

Solubility curves (binodals) and (liquid + liquid) equilibrium data of the soybean oil(1) + ethyl acetate(2) + ethanol(3) system were obtained by the cloud point method, using a jacketed $30 \mathrm{~cm}^{3}$ glass cell, as previously described (Dagostin et al., 2015a). All LLE measurements were carried out at local atmospheric pressure $(\sim 91.5 \mathrm{kPa})$. Binodal curves were determined at $298.15,313.15$ and $333.15 \mathrm{~K}$, while tie-lines where obtained at 298.15 and $313.15 \mathrm{~K}$. It was not possible to measure tie-lines at 333.15 due to the experimental difficulty in obtaining the liquid-phase split at this temperature; as the temperature is relatively high relative to the boiling point of solvents, the system became unstable when collecting the phases.

Because soybean oil is a complex mixture of different triacylglycerols and other minor compounds, for determining experimental and calculated phase compositions a single compound was considered. In other words, the oil was considered as a pseudocomponent, ignoring the variation and arrangements of its fatty acids composition.

Phase compositions were determined from refractive index and density correlations following the methodology described in the literature (Kanda et al., 2013). The calibration curve and phase samples were read in both a densitometer and refractometer at $293.15 \mathrm{~K}$. Phase samples were homogenized with known amounts of ethyl acetate when necessary (to obtain a single phase solution) which were taken into account for the final result. The values of the density and refractive index of ternary mixtures were used to fit the following multiple linear equation (Eq. 1) using the software Statistica 10 (StatSoft, Tulsa, USA):

$y=A+B . w_{2}+C \cdot w_{3}$

where $y$ can be either density or refractive index; $A$, $B, C$ are adjustable parameters for both density and refractive index; and $w_{2}$ and $w_{3}$ are the mass fractions of components 2 and 3 (ethyl acetate and ethanol), respectively. No interactive or polynomial parameters were considered in this equation due to their insignificance. Experimental and predicted composition deviations were lower than $0.5 \%$ for any point analyzed and lower than $0.3 \%$ in general (mean error). The equation that describes the calculated refractive index $\left(n^{\text {calc }}\right)$ at $298.15 \mathrm{~K}$ as a function of $w_{2}$ and $w_{3}$ is given by:

$n^{\text {calc }}=1.47139-0.11116 w_{2}-0.11177 w_{3}$

where the error of each parameter is $A \pm 4.55 \times 10^{-4}$, $B \pm 2.20 \times 10^{-3}$, and $C \pm 4.56 \times 10^{-4}$. The equation that describes the calculated density $\left(\rho^{\text {calc }}\right)$ at $298.15 \mathrm{~K}$ as a function of $w_{2}$ and $w_{3}$ is given by:

$\rho^{\text {calc }}=0.91526-0.04081 w_{2}-0.13049 w_{3}$

where, the error of each parameter is $\mathrm{A} \pm 1.25 \times 10^{-4}$, $\mathrm{B} \pm 6.05 \times 10^{-3}$, and $\mathrm{C} \pm 1.25 \times 10^{-4}$. Both models presented a $\mathrm{R}^{2}$ higher than 0.99 for the calibration data. Experimental tie-line compositions were obtained by minimizing an objective function $(O F$, Eq. 4) through the Generalized Reduced Gradient method on Microsoft ${ }^{\circledR}$ Excel.

$O F=\sum_{j=1}^{N P} \sum_{i=1}^{n f}\left(\left|n_{i j}^{\exp }-n_{i j}^{\text {calc }}\right|\right)^{2}+\left(\left|\rho_{\mathrm{ij}}^{\exp }-\rho_{i j}^{\text {calc }}\right|\right)^{2}$

where $n_{i j}^{\text {calc }}$ and $n_{i j}{ }^{\text {exp }}$ are the calculated and experimental refractive indexes, and $\rho_{i j}^{c a l c}$ and $\rho_{i j}^{\exp }$ are the calculated and experimental densities of tie-line $i$ in the phase $j ; N P$ is the total number of tie-lines and $n f$ is the total number of phases. Mass fractions $w_{2}$ and $w_{3}$ (ethyl acetate and ethanol, respectively) were considered decision variables in the optimization procedure of the objective function above, while $w_{l}$ (soybean oil) was obtained by mass balance.

\section{LLE modeling}

LLE experimental data obtained in this work were modeled using the NRTL model for the activity coefficient calculation using a temperature-dependent equation, as presented by Dagostin et al. (2015a). The adjusted binary interaction parameters take into account the interaction between solvents and oil (as a pseudo component). This consideration is equivalent to assuming that the partition coefficient is the same for all compounds of soybean oil. In the present study, the temperature dependence of the energetic parameters $\Delta g_{i j}$ was considered through the following equations:

$\Delta a_{i j}=A_{i j}+B_{i j} T$

where

$\Delta g_{i j}=\Delta a_{i j}$ 
and

$\Delta \tau_{i j}=\exp \left(-\alpha_{i j} \Delta g_{i j}\right)$

The algorithm presented by Ferrari et al. (2009) was applied for LLE calculations and parameter estimation of the NRTL model, in which liquid-liquid equilibrium calculations are performed by applying the liquid-liquid flash calculation with a phase stability test. A weighted least square objective function was used to optimize the binary interaction parameters for the thermodynamic model, as presented in equation (8).

$\min O F=\sum_{k=1}^{N P} \sum_{j=1}^{n f} \sum_{i=1}^{n c} \frac{\left(w_{i j k}^{c a l c}-w_{i j k}^{e x p}\right)^{2}}{\sigma_{i j}^{2}}$

where $w_{i j k}^{\text {calc }}$ and $w_{i j k}{ }^{\text {exp }}$ are the calculated and experimental mass fractions of component $i$ in phase $j$ for the $k$ tie-line, $N P$ is the total number of tie-lines, $n f$ is the total number of phases, $n c$ is the number of compounds in the system and $\sigma_{i j}^{2}$ is the estimated variance of compound $i$ in phase $j$ and it was calculated from the standard uncertainty $u(w)$.

For the minimization of the objective function (Equation 8), the Particle Swarm Optimization algorithm was used (Ferrari et al., 2009) for obtaining an initial guess, while the modified Simplex method (Press et al., 1992) was used for reaching the final value for the binary interaction parameters. To evaluate the correlation of calculated values from the NRTL model and experimental data, the root mean square deviation ( $r m s d)$ was calculated by equation (9):

$r m s d=100 \sqrt{\frac{\sum_{k=1}^{N P} \sum_{j=1}^{n f} \sum_{i=1}^{n c}\left(w_{i j k}^{c a l c}-w_{i j k}^{e x p}\right)^{2}}{N P \times n f \times n c}}$

\section{Extraction apparatus and experimental procedure}

Extractions were performed in a batch system using a pre-weighed amount of soybean flakes and a solvent to solid (raw material) mass ratio of $4: 1(\mathrm{~g} / \mathrm{g})$ at 298.15, 313.15 and $328.15 \mathrm{~K}$. Kinetics at $298.15 \mathrm{~K}$ were obtained in a previous work and used here as a means of comparison (Dagostin et al., 2015b). In this extraction step, temperatures up to $328.15 \mathrm{~K}$ were used to avoid the solvent mass loss during the extraction kinetic sampling, which could compromise the solvent to solid ratio. In addition, at $313.15 \mathrm{~K}$ a small content of ethyl acetate (around $15 \mathrm{wt} \%$ ) is enough to solubilize the ternary system.
Extraction took place in sealed Erlenmeyer flasks $(50 \mathrm{~mL})$ under vigorous shaking and water bath heating. The solvents used were anhydrous ethanol mixed with 5 and $10 \%$ ethyl acetate $(95 \%$ ethanol $+5 \%$ ethyl acetate, and $90 \%$ ethanol $+10 \%$ ethyl acetate). At the end of a predetermined extraction time $(1,2,5,10$, $15,30,60,90,120$ and $180 \mathrm{~min}$ ), the bulk phase was immediately collected using a syringe fitted with a paper membrane $(14 \mu \mathrm{m})$, transferred to glass tubes and covered. Each experiment was carried out at least in duplicate. The oily extract was determined gravimetrically by evaporating the collected samples (at 313.15 $\mathrm{K}$ for $24 \mathrm{~h}$ ). The volatile fraction was considered to be ethanol and ethyl acetate, while the heavier fraction was composed of crude soybean oil. A mass balance was used to calculate the amount of crude oil extracted (Equation 10).

Yield $(\%)=\frac{M_{\text {solv }}}{M_{\text {soy }}}\left(\frac{M_{\text {evap }}-M_{\text {tube }}}{M_{T S}-M_{\text {evap }}}\right) \times 100$

where Yield (\%) is the crude soybean oil fraction ( $\mathrm{g}$ oil per $100 \mathrm{~g}$ soybean flakes), $M_{\text {solv }}$ and $M_{\text {soy }}$ are the solvent and soybean weight used in the extraction process, respectively. $M_{\text {evap }}$ is the weight of the glass tube with the evaporated samples, $M_{\text {tube }}$ is the empty tube weight and $M_{T S}$ is the weight of the tube with the collected sample. Extraction yields are expressed as the amount of extract $(\mathrm{g})$ per $100 \mathrm{~g}$ of soybean.

\section{Mass transfer kinetic model (MTKM)}

Experimental kinetic data for crude soybean oil extraction were used to fit a mass transfer model based on Fick's law of diffusion, as previously described (Dagostin et al., 2015b). This model considers the soybean flakes as infinite slabs immersed in a well-stirred solvent of infinite volume. The basic assumptions used in this work to simplify the problems of mass transfer were:

(a) The soybean flakes are symmetrical infinite plates measuring $2 L$.

(b) The matrix is considered to be a porous pseudo-homogeneous medium. The concentration of solute in the solid particle depends on time and thickness.

(c) The crude oil is uniformly distributed in the soybean flakes before the extraction process takes place.

(d) Solvent and solute consists of a homogeneous mixture. Soybean oil concentration in the solvent depends only on time. 
(e) The extraction process is a phenomenon of diffusion, where the diffusivity is constant.

(f) The diffusion of compounds occurs in parallel and they do not interact with each other.

(g) There is no external mass transfer. The concentration of solute in the bulk solvent is the same as the concentration of solute in the solvent at the interior of the solid matrix.

(h) The bulk solvent was considered a liquid of infinite volume. The slab is washed by a liquid constantly kept pure. This assumption resulted in a good model fitting and was considered in this case to simplify the calculations.

The initial and boundary conditions used for the modeling purpose were:

$$
\begin{array}{llll}
\text { Initial } & t=0, & C=C_{0}, & -L<x<L ; \\
\text { Boundary } & t>0, & (\partial C / \partial x)=0, & x=0 ; \\
& t>0, & C=C_{\mathrm{i}}, & x= \pm L ;
\end{array}
$$

where $C_{0}$ and $C_{i}$ are the initial and interfacial concentrations of solute in the particle. Considering the above assumptions and boundary conditions applied, the corresponding model is expressed (Equation 11) as already described by Crank (1975).

$$
\frac{M}{M_{\infty}}=1-\frac{8}{\pi^{2}} \sum_{n=0}^{\infty} \frac{1}{(2 n+1)^{2}} \exp \left\{-\frac{(2 n+1)^{2} \pi^{2} D t}{4 L^{2}}\right\}
$$

where $M$ and $M_{\infty}$ are the amount of crude soybean oil transferred at a given time and at infinite time, respectively $(\mathrm{g}), D$ is the diffusivity of this solute inside the particle $\left(\mathrm{mm}^{2} \mathrm{~min}^{-1}\right)$ and $t$ is the extraction time (min). In terms of solute concentration, Equation 11 can be rewritten as:

$$
\left(\frac{C_{\infty}-C}{C_{\infty}}\right)=\frac{8}{\pi^{2}} \sum_{n=0}^{\infty} \frac{1}{(2 n+1)^{2}} \exp \left\{-\frac{(2 n+1)^{2} \pi^{2} D t}{4 L^{2}}\right\}
$$

where $C$ and $C_{\infty}$ are the solute concentration in the solid particle $(\mathrm{w} / \mathrm{w})$ at a given time and after infinite time, respectively. The numerical approach applied to all models was based on the minimization of a chi-square function involving the measured and calculated results using the Levenberg-Marquardt optimization method.

The goodness of fit for the kinetic model was calculated by the average relative deviation $(A R D(\%)$, Equation 13), and the root mean square error (RMSE, Equation 14).

$$
\begin{gathered}
A R D(\%)=\frac{1}{n} \sum_{i=1}^{n}\left|\frac{C_{\text {exp }}-C_{\text {fit }}}{C_{\text {exp }}}\right|_{i} \times 100 \\
\operatorname{RMSE}\left(g_{\text {oil }} g_{s}{ }^{-1}\right)=\sqrt{\sum_{i=1}^{n} \frac{\left(C_{\text {exp }}-C_{f i t}\right)^{2}}{n}}
\end{gathered}
$$

where $n$ is the number of experimental data collected, $C_{\text {exp }}$ and $C_{f i t}$ are the concentrations of crude oil obtained experimentally and estimated by the model, respectively, and $g_{\text {oil }}$ and $g_{s}$ correspond to the mass of crude oil and soybean flakes, respectively.

\section{Thermodynamic assessment}

The distribution coefficient $(K)$ for the liquid-solid (extraction) systems was calculated by:

$$
K=\frac{C_{\infty}}{C_{s}}=\frac{C_{\infty}}{C_{0}-C_{\infty}}
$$

where values of $C_{0}$ were determined experimentally, while values of $C_{\infty}$ were obtained from the kinetic model fitting. Thermodynamic parameters of enthalpy change $\Delta H^{\circ}\left(\mathrm{kJ} \mathrm{mol}^{-1}\right)$ and entropy change $\Delta S^{\circ}\left(\mathrm{J} \mathrm{mol}^{-1} \mathrm{~K}^{-1}\right)$ for the crude oil extraction were calculated by a linear fit of the Van't Hoff equation (Equation 16), and the Gibbs energy change $\left(\Delta G^{\circ}, \mathrm{kJ} \mathrm{mol}^{-1}\right)$ was determined according to Equation 17.

$$
\ln K=-\frac{\Delta H^{\circ}}{R T}+\frac{\Delta S^{\circ}}{R}
$$

$\Delta G^{\circ}=\Delta H^{\circ}-T \Delta S^{\circ}$

where $R$ is the universal gas constant $\left(\mathrm{J} \mathrm{mol}^{-1} \mathrm{~K}^{-1}\right)$. In order to find the values of $\Delta G^{\circ}$, the standard deviations of $\Delta H^{\circ}$ and $\Delta S^{\circ}$ were propagated considering the extraction to be an isothermal process. Thus, the standard deviation for the change in standard Gibbs free energy was obtained by Equation 18, where $\sigma$ is the standard deviation of each parameter.

$$
\sigma_{\Delta G^{\circ}}=\left|\left(\frac{\partial \Delta G^{\circ}}{\partial \Delta H^{\circ}}\right)\right| \sigma_{\Delta H^{\circ}}+\left|\left(\frac{\partial \Delta G^{\circ}}{\partial \Delta S^{\circ}}\right)\right| \sigma_{\Delta S^{\circ}}=\sigma_{\Delta H^{\circ}}+T \sigma_{\Delta S^{\circ}}
$$




\section{RESULTS AND DISCUSSION}

Liquid-liquid equilibrium curves for the system (anhydrous ethanol (1) + soybean oil (2) + ethyl acetate (3))

Experimental binodal data for the ternary system soybean oil (1) + ethyl acetate (2) + anhydrous ethanol (3) are presented in Table 1, for three different temperatures. Experimental tie-lines for this ternary system are presented in Table 2, at $298.15 \mathrm{~K}$ and $313.15 \mathrm{~K}$.

Figure 1 presents the experimental binodal and tielines, and also calculated values of binodal curves and tie-lines from the NRTL model. It is worth mentioning that, at $333.15 \mathrm{~K}$, it was not possible to measure the tie-lines due to the high miscibility of the system; however, it is possible to see that the NRTL model predicted the two-liquid region with accuracy. Binary interaction parameters of the NRTL model fitted for this ternary system are presented in Table 3 . It is seen that the NRTL model with a temperature-dependent function (Equation 5-7) was capable of correlating well all the LLE data for the systems soybean oil (1) + ethyl acetate (2) + ethanol (3).

Table 1: Binodal curves for the systems soybean oil $\left(w_{1}\right)+$ ethyl acetate $\left(w_{2}\right)+$ anhydrous ethanol $\left(w_{3}\right)$ at different temperatures, in mass fraction.

\begin{tabular}{|c|c|c|c|c|c|c|c|c|}
\hline \multicolumn{3}{|c|}{ 298.15 K } & \multicolumn{3}{|c|}{$313.15 \mathrm{~K}$} & \multicolumn{3}{|c|}{$333.15 \mathrm{~K}$} \\
\hline$w_{1}$ & $w_{2}$ & $w_{3}$ & $w_{1}$ & $w_{2}$ & $w_{3}$ & $w_{1}$ & $w_{2}$ & $w_{3}$ \\
\hline 0.0495 & 0.0000 & 0.9505 & 0.0796 & 0.0000 & 0.9204 & 0.1951 & 0.0000 & 0.8049 \\
\hline 0.0738 & 0.0787 & 0.8475 & 0.1007 & 0.0385 & 0.8608 & 0.2104 & 0.0061 & 0.7836 \\
\hline 0.1020 & 0.1146 & 0.7834 & 0.1137 & 0.0573 & 0.8290 & 0.2250 & 0.0116 & 0.7635 \\
\hline 0.1228 & 0.1322 & 0.7450 & 0.1290 & 0.0720 & 0.7989 & 0.2434 & 0.0162 & 0.7404 \\
\hline 0.1495 & 0.1508 & 0.6997 & 0.1516 & 0.0881 & 0.7602 & 0.2662 & 0.0194 & 0.7144 \\
\hline 0.1764 & 0.1642 & 0.6594 & 0.1822 & 0.1039 & 0.7139 & 0.3021 & 0.0222 & 0.6757 \\
\hline 0.2088 & 0.1740 & 0.6172 & 0.2024 & 0.1097 & 0.6878 & 0.4023 & 0.0233 & 0.5744 \\
\hline 0.2357 & 0.1775 & 0.5867 & 0.2165 & 0.1126 & 0.6709 & 0.4550 & 0.0187 & 0.5263 \\
\hline 0.2689 & 0.1784 & 0.5527 & 0.2557 & 0.1181 & 0.6262 & 0.4947 & 0.0173 & 0.4881 \\
\hline 0.3046 & 0.1764 & 0.5190 & 0.2901 & 0.1193 & 0.5906 & 0.5136 & 0.0147 & 0.4718 \\
\hline 0.3355 & 0.1734 & 0.4911 & 0.3271 & 0.1172 & 0.5557 & 0.5539 & 0.0107 & 0.4354 \\
\hline 0.3582 & 0.1706 & 0.4713 & 0.3578 & 0.1148 & 0.5274 & 0.5776 & 0.0072 & 0.4151 \\
\hline 0.3960 & 0.1674 & 0.4366 & 0.3905 & 0.1118 & 0.4976 & 0.5963 & 0.0043 & 0.3994 \\
\hline 0.4213 & 0.1659 & 0.4128 & 0.4171 & 0.1101 & 0.4727 & 0.6205 & 0.0000 & 0.3795 \\
\hline 0.4420 & 0.1630 & 0.3950 & 0.4664 & 0.1036 & 0.4299 & & & \\
\hline 0.4642 & 0.1593 & 0.3764 & 0.4944 & 0.0999 & 0.4057 & & & \\
\hline 0.4976 & 0.1534 & 0.3490 & 0.5229 & 0.0961 & 0.3810 & & & \\
\hline 0.5223 & 0.1482 & 0.3295 & 0.5486 & 0.0911 & 0.3603 & & & \\
\hline 0.5573 & 0.1396 & 0.3031 & 0.5887 & 0.0820 & 0.3293 & & & \\
\hline 0.6008 & 0.1266 & 0.2725 & 0.6238 & 0.0719 & 0.3043 & & & \\
\hline 0.6439 & 0.1118 & 0.2443 & 0.6568 & 0.0618 & 0.2814 & & & \\
\hline 0.6924 & 0.0924 & 0.2152 & 0.6902 & 0.0503 & 0.2595 & & & \\
\hline 0.7355 & 0.0731 & 0.1914 & 0.7227 & 0.0369 & 0.2404 & & & \\
\hline 0.7867 & 0.0477 & 0.1655 & 0.7542 & 0.0240 & 0.2218 & & & \\
\hline 0.8243 & 0.0284 & 0.1473 & 0.7756 & 0.0153 & 0.2091 & & & \\
\hline 0.8740 & 0.0000 & 0.1260 & 0.8040 & 0.0000 & 0.1960 & & & \\
\hline
\end{tabular}

Standard uncertainties $u$ are: $u(T)=0.5 \mathrm{~K}$ and $u(w) \leq 0.0503$. Experimental pressure is atmospheric pressure. 
Table 2: Experimental tie lines for the system soybean oil $\left(w_{l}\right)+$ ethyl acetate $\left(w_{2}\right)+$ anhydrous ethanol $\left(w_{3}\right)$, in mass fraction basis.

\begin{tabular}{cccccc}
\hline \multicolumn{3}{c}{ Ethanol rich phase (I) } & \multicolumn{3}{c}{ Oil rich phase (II) } \\
\hline $\boldsymbol{w}_{\boldsymbol{I}}$ & $\boldsymbol{w}_{2}$ & $\boldsymbol{w}_{\mathbf{3}}$ & $\boldsymbol{w}_{\boldsymbol{I}}$ & $\boldsymbol{w}_{2}$ & $\boldsymbol{w}_{3}$ \\
\hline 0.0761 & 0.0570 & 0.8669 & 0.8078 & 0.0118 & 0.1805 \\
0.1025 & 0.0900 & 0.8075 & 0.7583 & 0.0442 & 0.1975 \\
0.1036 & 0.0929 & 0.8035 & 0.7452 & 0.0531 & 0.2017 \\
0.1372 & 0.1334 & 0.7295 & 0.6813 & 0.0865 & 0.2322 \\
0.1923 & 0.1590 & 0.6487 & 0.6124 & 0.1142 & 0.2734 \\
& \multicolumn{2}{c}{$\boldsymbol{T}=3 \mathbf{3 1 3 . 1 5} \boldsymbol{K}$} & & \\
0.1267 & 0.0436 & 0.8297 & 0.7345 & 0.0183 & 0.2473 \\
0.1658 & 0.0867 & 0.7475 & 0.6611 & 0.0488 & 0.2902 \\
0.2259 & 0.1177 & 0.6564 & 0.5708 & 0.0777 & 0.3515 \\
\hline
\end{tabular}

Standard uncertainties $u$ are: $u(T)=0.5 \mathrm{~K}$ and $u(w) \leq 0.0503$. Experimental pressure is atmospheric pressure

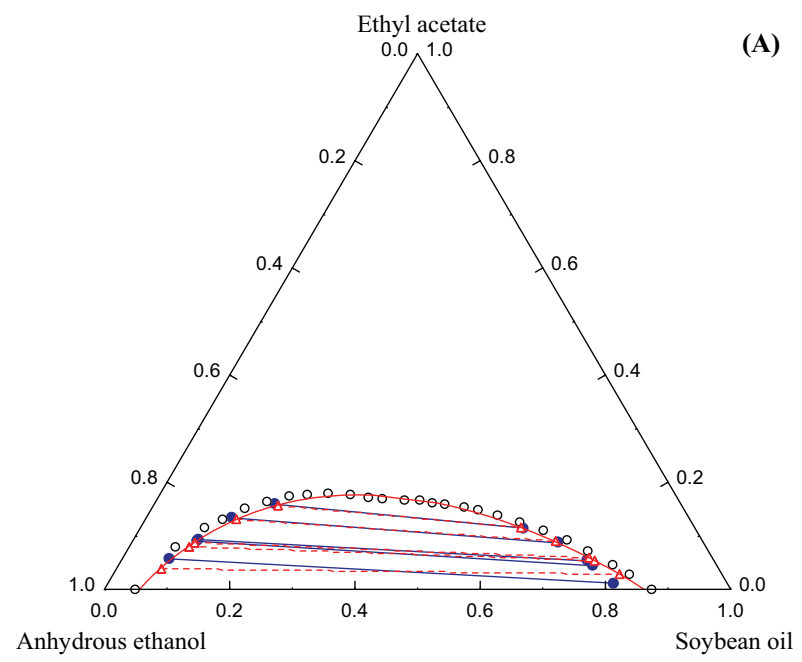

(A)
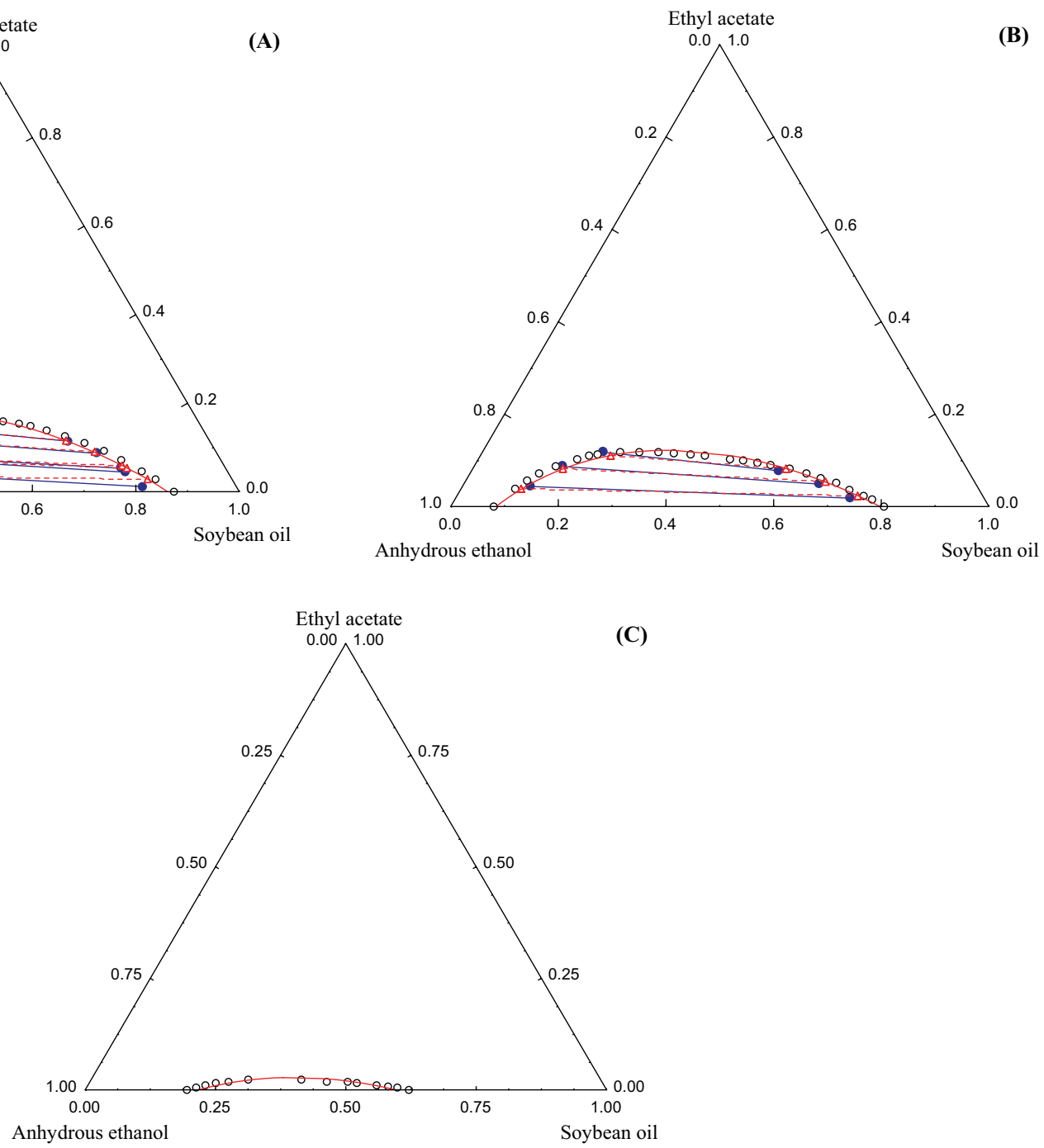

Figure 1: Ternary diagram for the system soybean oil(1) + ethyl acetate(2) + ethanol(3), at (A) $298.15 \mathrm{~K}$, (B) 313.15 K and (C) $333.15 \mathrm{~K}$. Experimental tie-lines $(-)$ and binodals $(\circ)$, and tie-lines $\left(-\triangle^{-}\right)$and binodals $(-)$ calculated with the NRTL model. 
Table 3: Fitted binary interaction parameters of the NRTL model for the system soybean oil $\left(w_{l}\right)+$ ethyl acetate $\left(w_{2}\right)+$ ethanol $\left(w_{3}\right)$.

\begin{tabular}{|c|c|c|c|c|c|}
\hline$i-j$ & $A_{i j} / K$ & $A_{j i} / K$ & $\boldsymbol{B}_{i j}$ & $\boldsymbol{B}_{j i}$ & $\alpha_{i j}$ \\
\hline $1-2$ & -303.67 & 210.10 & -412.58 & 359.70 & 0.2 \\
\hline $1-3 *$ & 3774.80 & 44.50 & -1289.43 & 491.26 & 0.4544 \\
\hline $2-3$ & 1087.68 & -137.62 & -595.93 & 206.80 & 0.2 \\
\hline$R M S D x 100$ & 0.097 & & & & \\
\hline
\end{tabular}

*Values used from Dagostin et al. (2015a)

all $\alpha_{i j}$ values were used as fixed.

From the experimental LLE data for the system soybean oil (1) + ethyl acetate (2) + anhydrous ethanol (3) at 298.15, 313.15 and $333.15 \mathrm{~K}$ (Figure 1) it is possible to observe that the LLE curves present a very similar behavior. Temperature variations strongly influenced the solubility of the system, evidenced by a decrease in the heterogeneous region as the temperature is increased.

The mixture comprising soybean oil + anhydrous ethanol is partially soluble in normal conditions of pressure and temperature, where the oil-rich region presents a higher solubility range than that rich in alcohol (Dagostin et al., 2015a). Regarding the binary mixtures of soybean oil + ethyl acetate and anhydrous ethanol + ethyl acetate, both showed complete solubility in the temperature range studied. Analyzing the results at $333.15 \mathrm{~K}$, it can be noted that a small amount of ester is enough to turn the system completely homogeneous at any ratio of soybean oil to anhydrous ethanol. From the experimental results presented in this work it can be observed that the complete solubility of the system is achieved at an ethyl acetate content around $17.8,11.9$ and $2.3 \%$ (mass) for temperatures of $298.15,313.15$ and $333.15 \mathrm{~K}$, respectively.

In a previous work (Dagostin et al., 2015a), the LLE for systems involving anhydrous ethanol + soybean oil + biodiesel were studied and the existence of immiscibility regions of slightly larger size than those for the systems presented herein was verified. This difference was attributed to the fact that biodiesel is essentially a mixture of esters of higher molecular weight than ethyl acetate. A higher amount of biodiesel should be used to reach the complete homogeneity of the system (soybean oil + ethanol). In addition, systems containing ethyl acetate and biodiesel differed in the binodal curvature shapes, in which those involving ethyl acetate were steeper to the left, while binodal curves of systems containing biodiesel were steeper to the right. The data obtained for ethyl acetate systems also resulted in a better-resolved curve, probably because a pure ester was used in this case. Using ethyl acetate as a co-solvent in the soybean oil extraction with anhydrous ethanol seems to be a promising process, since it promotes the solubility of the oil and presents an ease of recovery by conventional methods.

\section{Kinetic extractions}

Soybean flakes used in the extraction experiments presented a moisture content of $9.33 \pm 0.11 \%$, with a mean thickness value of $0.220 \pm 0.019 \mathrm{~mm}$, and 25.58 $\pm 0.25 \%$ crude oil content (Soxhlet, ethanol), as previously verified (Dagostin et al., 2015b). In this previous work, the extraction time and solvent to soybean ratio were fixed at $2 \mathrm{~h}$ and 4:1 (solvent: soybean, mass basis), respectively, assuring a sufficient extraction time to reach equilibrium and the presence of enough solvent to achieve maximum extraction (avoiding the use of unnecessarily higher amounts of solvent).

Figure 2 shows the kinetic curves for crude soybean oil extraction with anhydrous ethanol $(\mathrm{EtOH})$ and its mixtures with 5\% (Et5A) and 10\% (Et10A) of ethyl acetate at 298.15 (A), 313.15 (B) and $328.15 \mathrm{~K}(\mathrm{C})$. It can be seen that the extraction rates are very similar until approximately 10 minutes of contact between solvent and soybean flakes and the equilibrium conditions reached (long time of extraction) are different depending on the type of the solvent used. From these results, it can be seen that the soybean oil solubility increases as ethyl acetate in ethanol increased. The extraction yields at equilibrium conditions were $15.2 \%$, $18.8 \%$ and $21.6 \%$ using the solvents EtOH, Et5A and Et10A, respectively. 

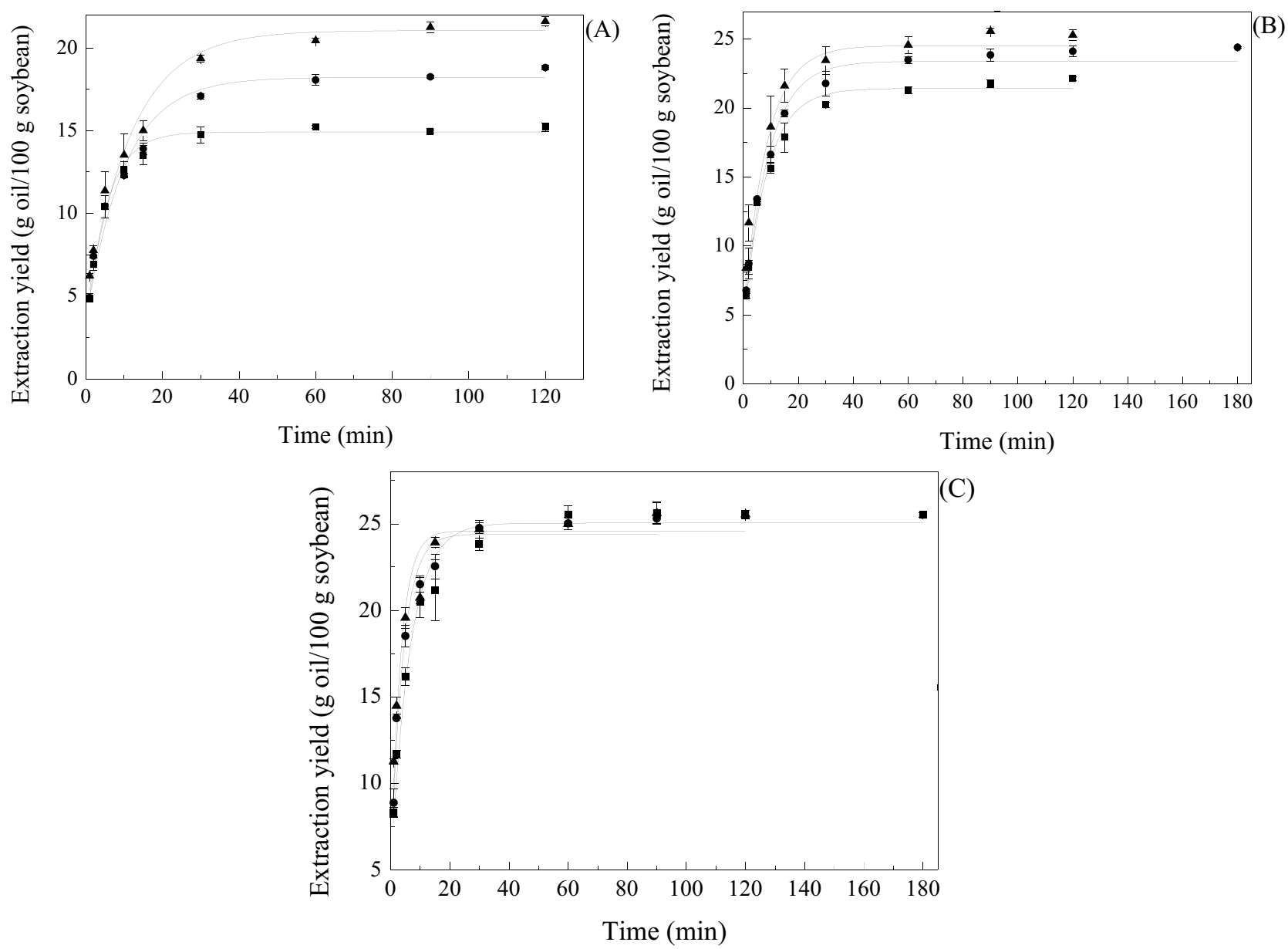

Figure 2: Kinetic experiments at 298.15 (A), 313.15 (B) and 328.15 K (C) using: anhydrous ethanol (匹, Dagostin et al., 2015a); $95 \%$ anhydrous ethanol $+5 \%$ ethyl acetate $(\bullet) ; 90 \%$ anhydrous ethanol $+10 \%$ ethyl acetate $(\boldsymbol{\Delta})$. The solid line corresponds to the mass transfer model.

The same behavior observed in the overall extraction curves at $298.15 \mathrm{~K}$ was observed at 313.15 and $328.15 \mathrm{~K}$. Similar extraction rates up to $10-15$ minutes of contact (regardless of the solvent used) and higher total amount of crude oil extracted for those systems containing ester. However, at $313.15 \mathrm{~K}$ a smaller difference in the extraction capacity (at equilibrium condition) for the three solvents was observed when compared to the results at $298.15 \mathrm{~K}$. At $328.15 \mathrm{~K}$ (Figure 2C), significant differences were not observed when using anhydrous ethanol and its mixture with 5\% and $10 \%$ ethyl acetate on the total amount of crude soybean oil extracted. Moreover, at this last condition the extraction rates were similar for all three types of solvents used.
In order to describe the extraction process, a model based on mass transfer by diffusion in an infinite flat plate was adjusted to the experimental data. The constants obtained for the model and the statistical results are shown in Table 4. The mass transfer model was fitted to the experimental data considering the sum of several $(n)$ terms in Eq. 12. In general, the fittings presented different parameter values up to the fourth term. However, considering the high order coefficients ( $n$ number) greater deviations were observed (data not shown). Thus, the mass transfer equation was truncated at the first term $(n=0)$ in order to better describe the experimental data. The coefficient of determination $\left(\mathrm{R}^{2}\right)$ and $A R D$ values ranged from 0.9278 to 0.9864 and 3.13 to $7.36 \%$, respectively. 
Table 4: Parameters of the mass transfer kinetic model (MTKM) fits and their standard deviations for crude soybean oil extraction using (anhydrous ethanol + ethyl acetate) mixtures at 298.15, 313.15 and $328.15 \mathrm{~K}$.

\begin{tabular}{|c|c|c|c|c|c|c|}
\hline $\mathbf{T}(\mathbf{K})$ & Solvent & $\begin{array}{c}C_{\infty} C^{a, b} \\
\left(g_{0 i l} g_{s}^{-1}\right)\end{array}$ & $\begin{array}{c}k^{\mathbf{c}} \\
\left(\mathbf{m i n}^{-1}\right)\end{array}$ & $R^{2}$ & $A A R D(\%)$ & $\begin{array}{l}R M S E^{b} \\
\left(g_{\text {oil }} g_{s}^{-1}\right)\end{array}$ \\
\hline \multirow{3}{*}{298.15} & $\mathrm{EtOH}^{\mathrm{d}}$ & $0.1491 \pm 0.0014$ & $0.0745 \pm 0.0037$ & 0.9827 & 3.13 & 0.005 \\
\hline & Et5A & $0.1822 \pm 0.0030$ & $0.0403 \pm 0.0031$ & 0.9743 & 5.36 & 0.007 \\
\hline & Et10A & $0.2105 \pm 0.0041$ & $0.0345 \pm 0.0030$ & 0.9678 & 7.11 & 0.010 \\
\hline \multirow{3}{*}{313.15} & $\mathrm{EtOH}^{\mathrm{d}}$ & $0.2142 \pm 0.0021$ & $0.0495 \pm 0.0023$ & 0.9801 & 4.50 & 0.008 \\
\hline & Et5A & $0.2374 \pm 0.0025$ & $0.0433 \pm 0.0023$ & 0.9864 & 3.72 & 0.007 \\
\hline & Et10A & $0.2410 \pm 0.0064$ & $0.0520 \pm 0.0070$ & 0.9593 & 7.36 & 0.012 \\
\hline \multirow{3}{*}{328.15} & $\mathrm{EtOH}^{\mathrm{d}}$ & $0.2505 \pm 0.0025$ & $0.0633 \pm 0.0035$ & 0.9659 & 4.63 & 0.011 \\
\hline & Et5A & $0.2440 \pm 0.0038$ & $0.0999 \pm 0.0084$ & 0.9666 & 4.83 & 0.010 \\
\hline & Et10A & $0.2459 \pm 0.0043$ & $0.1202 \pm 0.0126$ & 0.9278 & 5.38 & 0.013 \\
\hline
\end{tabular}

${ }^{\mathrm{a}} C_{\infty}$ is the equilibrium concentration.

${ }^{\mathrm{b}} g_{\text {oil }}$ and $g_{s}$ correspond to the units (grams) of crude soybean oil and soybean flakes, respectively.

c parameter $k$ for $M T K M$ corresponds to $D / L^{2}$ from Equation (7), for $L=0.110 \mathrm{~mm}$.

${ }^{\mathrm{d}}$ Dagostin et al. (2015b).

The values are the parameters $\left(C_{\infty}\right.$ and $\left.k\right) \pm$ standard deviation.

In terms of maximum extraction yield, all kinetics of extraction at $328.15 \mathrm{~K}$ were comparable to that of Et $10 \mathrm{~A}$ at $313.15 \mathrm{~K}$, which means that using $10 \%$ ethyl acetate in ethanol at $313.15 \mathrm{~K}$ could be an alternative to diminish the energy consumption for a batch system extraction. However, taking into account the extraction time, increases in the ethyl acetate content and/or applying higher temperatures leads to an increase in the extraction rates and extraction yield. However, it is worth mentioning that the choice of process conditions will depend on a technical and economic viability evaluation.

From the kinetic extraction curves, considering the data at equilibrium (MTKM) and assuming that the micelle is composed only of ethanol + pure soybean oil + ethyl acetate (Figure 3), it can be seen that there is a deviation from these data (extraction equilibrium) compared to the LLE data (Figure 1). This deviation is related to the presence of several other components extracted from the soybean flakes, assigning to the water the role of main interfering agent, as related in a previous work (Dagostin et al., 2015a). Assuming that all the moisture present in the soybean flakes migrate to the bulk solution, it would account for an approximately $2 \%$ increase in the water content of the solvent. The presence of water will affect the solubility and extraction of oils to some extent, although this was not measured.

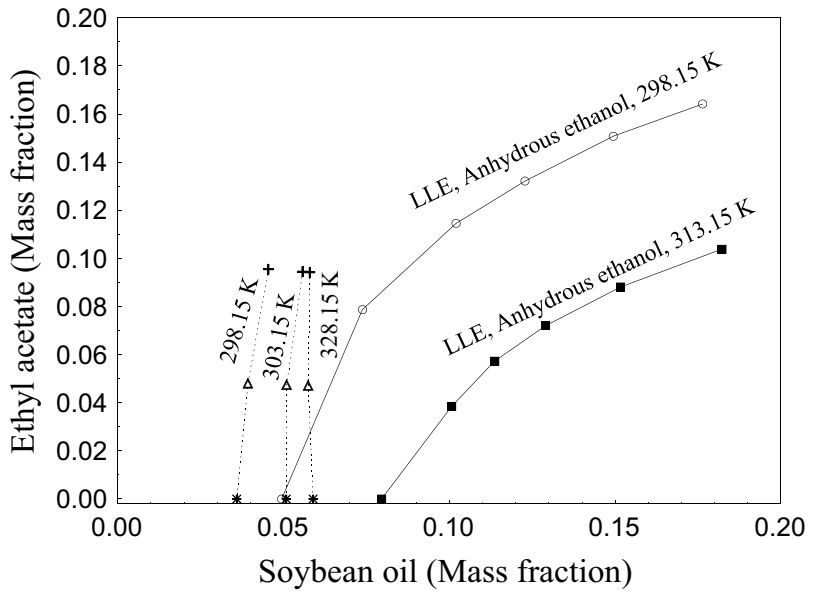

Figure 3: Equilibrium data $(*, \mathrm{EtOH} ; \Delta, \mathrm{Et5A}$; and + , Et10A, obtained from the kinetic model, MTKM) of the micelles considering only the pure components (ethanol + soybean oil + ethyl acetate) at 298.15, 313.15 and $328.15 \mathrm{~K}$. LLE data: anhydrous ethanol at 298.15 (०) and 313.15 K (匹) (from Figure 1).

According to the data obtained for the kinetics of extraction involving anhydrous ethanol and ethyl acetate (MTKM) (Table 4, Figure 2C), the maximum total extraction took place at $328.15 \mathrm{~K}$, for all solvents used. Through this figure it can be inferred that, using over $10 \%$ of ethyl acetate in anhydrous ethanol for extracting crude soybean oil at 298.15 and $313.15 \mathrm{~K}$ (in the 
conditions applied), at some point the total amount of oil extracted should be the same as the maximum, obtained at $328.15 \mathrm{~K}$. Comparing these curves, the mass fraction of ethyl acetate used to achieve this maximum extraction capability should be around $15 \%$ and $11 \%$ for extractions at 298.15 and $313.15 \mathrm{~K}$, respectively.

\section{Thermodynamic analysis of the extraction process}

A thermodynamic analysis was performed based on concentration values obtained from the mass transfer model (MTKM) fit to the experimental data. The parameters $K, \Delta H^{\mathrm{o}}, \Delta S^{\mathrm{o}}$ and $\Delta G^{\mathrm{o}}$ are shown in Table 5 , along with the coefficient of determination from the Van't Hoff equation (Eq. 16) fit.

Enthalpy changes $\left(\Delta H^{\circ}\right)$ were positive for all extractions evaluated, i.e., the extraction processes require energy due to their endothermic character. In a previous work, involving the same extraction conditions used in this study and biodiesel as a co-solvent, slightly higher values of $\Delta H^{\mathrm{o}}$ were obtained for higher biodiesel fractions in ethanol (Dagostin et al., 2015b). In the present work, where these extractions involved ethyl acetate as co-solvent, the results of enthalpy change followed the opposite behavior. The enthalpy required for the crude soybean oil extraction decreased as higher amount of ethyl acetate were used as co-solvent in the process, which is an advantage from the energetic point of view.

Positive values of the entropy change, obtained in all extraction kinetics evaluated, indicate that the extraction process is irreversible. The deviations of $\Delta G^{\mathrm{o}}$ values were higher than the Gibbs energy change values. On average, these deviations were \pm 30.37 $\mathrm{kJ} . \mathrm{mol}^{-1}$ while $\Delta G^{\mathrm{o}}$ values were not higher than 11.61 $\mathrm{kJ} . \mathrm{mol}^{-1}$ (in absolute values). Both the $\Delta H^{\mathrm{o}}$ and T. $\Delta S^{\mathrm{o}}$ parameters have increased errors with similar magnitudes. Nevertheless, $\Delta G^{\mathrm{o}}$ values for the extraction procedures are presented in Table 5 as a basis for developing works in this area. Negative values for the Gibbs energy changes indicate that the process is spontaneous and product-favored.

\section{CONCLUSIONS}

Liquid-liquid equilibrium data for the system (anhydrous ethanol + soybean oil + ethyl acetate) at $\mathrm{T}=(298.15,313.15$ and $313.15 \mathrm{~K})$ were presented. The LLE were well correlated using the NRTL model with a temperature-dependent binary interaction parameter. Using higher temperatures allowed increasing the solubility of soybean oil in ethanol. These data were helpful for setting the operating conditions used in the extraction process. From the LLE obtained it was observed that ethyl acetate can be considered to be a good solubilizing agent for (ethanol + soybean oil) mixtures.

Overall curves of crude soybean oil extraction using mixtures of (anhydrous ethanol + ethyl acetate) as solvent were presented. At higher temperatures, higher extraction rates and amounts of solutes (at equilibrium) were obtained for all mixtures. At lower temperatures, the effect of using ethyl acetate as co-solvent was more pronounced in crude soybean oil extraction. It was found that $\Delta H^{\mathrm{o}}$ and $\Delta S^{\mathrm{o}}$ are positive and $\Delta G^{\mathrm{o}}$ is negative, indicating that these extraction processes are endothermic, irreversible and spontaneous. The use of ethyl acetate for recovery of crude soybean oil appears as a promising alternative for decreasing the energy demand of ethanolic extraction, since its effect becomes larger at lower temperatures.

Table 5: Distribution constants $(K)$ and the thermodynamic parameters $\left(\Delta H^{\mathbf{0}}, \Delta S^{\mathbf{0}}\right.$ and $\left.\Delta G^{\mathbf{0}}\right)$ for the extraction of crude soybean oil using anhydrous ethanol + ethyl acetate mixtures.

\begin{tabular}{|c|c|c|c|c|c|c|}
\hline Solvent & Temperature (K) & $K$ & $\begin{array}{c}\Delta H^{\mathbf{o}} \\
\left(\mathrm{kJ} \mathrm{mol}^{-1}\right)\end{array}$ & $\begin{array}{c}\Delta S^{\mathbf{o}} \\
\left(\mathrm{J} \mathrm{mol}^{-1} \mathrm{~K}^{-1}\right)\end{array}$ & $\begin{array}{c}\Delta G^{\mathbf{o}} \\
\left(\mathrm{kJ} \mathrm{mol}^{-1}\right)\end{array}$ & $\mathbf{R}^{2}$ \\
\hline \multirow{3}{*}{$\mathrm{EtOH}$} & 298.15 & 1.40 & $95.01 \pm 16.92$ & $320.02 \pm 54.14$ & -0.41 & 0.969 \\
\hline & 313.15 & 5.15 & & & -5.21 & \\
\hline & 328.15 & 47.26 & & & -11.61 & \\
\hline \multirow{3}{*}{ Et5A } & 298.15 & 2.48 & $58.02 \pm 16.86$ & $203.56 \pm 53.95$ & -2.67 & 0.922 \\
\hline & 313.15 & 12.90 & & & -5.72 & \\
\hline & 328.15 & 20.68 & & & -9.79 & \\
\hline \multirow{3}{*}{ Et10A } & 298.15 & 4.65 & $45.78 \pm 11.75$ & $167.30 \pm 37.63$ & -4.10 & 0.938 \\
\hline & 313.15 & 16.28 & & & -6.61 & \\
\hline & 328.15 & 24.84 & & & -9.96 & \\
\hline
\end{tabular}




\section{ACKNOWLEDGEMENTS}

This work was supported financially by the Conselho Nacional de Desenvolvimento Científíco e Tecnológico (CNPq, Grants 558836/2010-0 and 406737/2013-4), a Brazilian government agency for the advancement of science. Research scholarships were granted to M. L. C. (Grant 303573/2012-0) by CNPq. The authors are also grateful to IMCOPA for supplying the soybean flakes.

\section{REFERENCES}

Adam, F., Abert-Vian, M., Peltier, G., and Chemat, F., "Solvent-free" ultrasound-assisted extraction of lipids from fresh microalgae cells: A green, clean and scalable process, Bioresource Technology, 114, 457-465 (2012). https://doi.org/10.1016/j. biortech.2012.02.096

Araujo, G. S., Matos, L. J. B. L., Fernandes, J. O., Cartaxo, S. J. M., Gonçalves, L. R. B., Fernandes, F. A. N., and Farias, W. R. L., Extraction of lipids from microalgae by ultrasound application: Prospection of the optimal extraction method, Ultrasonics Sonochemistry, 20(1), 95-98 (2013). https://doi.org/10.1016/j.ultsonch.2012.07.027

Baümler, E. R., Carrín, M. E., and Carelli, A. A., Extraction of sunflower oil using ethanol as solvent, Journal of Food Engineering, 178, 190-197 (2016). https://doi.org/10.1016/j.jfoodeng.2016.01.020

Coelho, R., Kanda, L. R. S., Hamerski, F., Masson, M. L., and Corazza, M. L., Extraction of Kiwifruit Seed (Actinidia deliciosa) Oil Using Compressed Propane, Journal of Food Process Engineering, 39(4), 335-344 (2016). https://doi.org/10.1111/ jfpe. 12225

Crank, J., The mathematics of diffusion, Oxford University Press (2nd ed.). London: Oxford University Press (1975). https://doi. org/10.1016/0306-4549(77)90072-X

Cravotto, G., Boffa, L., Mantegna, S., Perego, P., Avogadro, M., and Cintas, P., Improved extraction of vegetable oils under high-intensity ultrasound and/or microwaves, Ultrasonics Sonochemistry, 15(5), 898-902 (2008). https://doi.org/10.1016/j. ultsonch.2007.10.009

Dagostin, J. L. A., Carpiné, D., and Corazza, M. L., Extraction of soybean oil using ethanol and mixtures with alkyl esters (biodiesel) as cosolvent: Kinetics and thermodynamics, Industrial Crops and Products, 74, 69-75 (2015). https://doi. org/10.1016/j.indcrop.2015.04.054
Dagostin, J. L. A., Mafra, M. R., Ramos, L. P., and Corazza, M. L., Liquid-liquid phase equilibrium measurements and modeling for systems involving \{soybean oil+ethyl esters $+($ ethanol+water $)\}$, Fuel, 141, 164-172 (2015). https://doi.org/10.1016/j. fuel.2014.10.049

de Melo, M. M. R., Silvestre, A. J. D., and Silva, C. M., Supercritical fluid extraction of vegetable matrices: Applications, trends and future perspectives of a convincing green technology, The Journal of Supercritical Fluids, 92, 115-176 (2014). https:// doi.org/10.1016/j.supflu.2014.04.007

dos Santos Freitas, L., de Oliveira, J. V., Dariva, C., Jacques, R. A., and Caramão, E. B., Extraction of Grape Seed Oil Using Compressed Carbon Dioxide and Propane: Extraction Yields and Characterization of Free Glycerol Compounds, Journal of Agricultural and Food Chemistry, 56(8), 2558-2564 (2008). https://doi.org/10.1021/ jf0732096

Eggers, R., Sievers, U., and Stein, W., High pressure extraction of oil seed, Journal of the American Oil Chemists' Society, 62(8), 1222-1230 (1985). https://doi.org/10.1007/BF02541832

Ferrari, J. C., Nagatani, G., Corazza, F. C., Oliveira, J. V., and Corazza, M. L., Application of stochastic algorithms for parameter estimation in the liquidliquid phase equilibrium modeling, Fluid Phase Equilibria, 280(1-2), 110-119 (2009). https://doi. org/10.1016/j.fluid.2009.03.015

Gandhi, A. P., Joshi, K. C., Jha, K., Parihar, V. S., Srivastav, D. C., Raghunadh, P., ... Tripathi, R. N., Studies on alternative solvents for the extraction of oil-I soybean, International Journal of Food Science and Technology, 38(3), 369-375 (2003). https://doi.org/10.1046/j.1365-2621.2003.00683.x

Hu, A. J., Feng, Q. Q., Zheng, J., Hu, X. H., Wu, C., and Liu, C. Y., Kinetic model and technology of ultrasound extraction of safflower seed oil, Journal of Food Process Engineering, 35(2), 278-294 (2012). https://doi.org/10.1111/j.17454530.2010.00589.x

Inui, K., Kurabayashi, T., and Sato, S., Direct synthesis of ethyl acetate from ethanol over $\mathrm{Cu}-\mathrm{Zn}-\mathrm{Zr}-\mathrm{Al}-\mathrm{O}$ catalyst, Applied Catalysis A: General, 237(12), 53-61 (2002). https://doi.org/http://dx.doi. org/10.1016/S0926-860X(02)00320-4

Kanda, L. R., Voll, F. A. P., and Corazza, M. L., LLE for the systems ethyl palmitate (palmitic acid) (1)+ethanol(2)+glycerol (water)(3), Fluid Phase Equilibria, 354, 147-155 (2013). https://doi. org/10.1016/j.fluid.2013.06.027 
Kemper, T. G., Oil Extraction, In F. Shahidi (Ed.), Bailey's Industrial Oil and Fat Products (v. 5) (6th ed., pp. 57-98). Hoboken: Wiley-Interscience (2005).

Koubaa, M., Mhemdi, H., and Vorobiev, E., Influence of canola seed dehulling on the oil recovery by cold pressing and supercritical $\mathrm{CO}_{2}$ extraction, Journal of Food Engineering, 182, 18-25 (2016). https:// doi.org/10.1016/j.jfoodeng.2016.02.021

Lee, A. K., Lewis, D. M., and Ashman, P. J., Disruption of microalgal cells for the extraction of lipids for biofuels: Processes and specific energy requirements, Biomass and Bioenergy, 46, 89-101 (2012). https://doi.org/10.1016/j. biombioe.2012.06.034

National Research Council - NRC, Prudent Practices in the Laboratory: Handling and Disposal of Chemicals. Washington, D.C., USA: National Academy Press (1995).

Nielsen, M., Junge, H., Kammer, A., and Beller, M., Towards a green process for bulk-scale synthesis of ethyl acetate: Efficient acceptorless dehydrogenation of ethanol, Angewandte Chemie - International Edition, 51(23), 5711-5713 (2012). https://doi.org/10.1002/anie.201200625

NIOSH - The National Institute for Occupational Safety and Health, NIOSH Pocket Guide to Chemical Hazards: $n$-Hexane (2017). Retrieved March 3, 2017, from http://www.cdc.gov/niosh/ npg/npgd0322.html

OSHA - Occupational Safety and Health Administration, OSHA Guidelines for $n$-Hexane (2017). Retrieved March 3, 2017, from https:// www.osha.gov/dts/chemicalsampling/data/ CH 245400.html

Pederssetti, M. M., Palú, F., da Silva, E. A., Rohling, J. H., Cardozo-Filho, L., and Dariva, C., Extraction of canola seed (Brassica napus) oil using compressed propane and supercritical carbon dioxide, Journal of Food Engineering, 102(2), 189-196 (2011). https://doi.org/10.1016/j.jfoodeng.2010.08.018

Press, W. H., Teukolsky, S. A., Vetterling, W. T., and Flannery, B. P., Numerical Recipes in Fortran 77: The Art of Scientific Computing, Transform (2nd ed., Vol. 1). Cambridge University Press (1992).

Rai, A., Mohanty, B., and Bhargava, R., Supercritical extraction of sunflower oil: A central composite design for extraction variables, Food Chemistry, 192, 647-659 (2016). https://doi.org/10.1016/j. foodchem.2015.07.070

Seth, S., Agrawal, Y. C., Ghosh, P. K., Jayas, D. S., and Singh, B. P. N., Oil extraction rates of soya bean using isopropyl alcohol as solvent, Biosystems Engineering, 97(2), 209-217 (2007). https://doi. org/10.1016/j.biosystemseng.2007.03.008

Stahl, E., Schuetz, E., and Mangold, H. K., Extraction of seed oils with liquid and supercritical carbon dioxide, Journal of Agricultural and Food Chemistry, 28(6), 1153-1157 (1980). https://doi. org/10.1021/jf60232a023

Thomas, G. C., Análise teórico-experimental da extração de óleo de soja em instalação industrial do tipo Rotocell. (2003).

Toda, T. A., Sawada, M. M., and Rodrigues, C. E. C., Kinetics of soybean oil extraction using ethanol as solvent: Experimental data and modeling, Food and Bioproducts Processing, 98, 1-10 (2016). https:// doi.org/10.1016/j.fbp.2015.12.003

Uquiche, E., Jeréz, M., and Ortíz, J., Effect of pretreatment with microwaves on mechanical extraction yield and quality of vegetable oil from Chilean hazelnuts (Gevuina avellana Mol), Innovative Food Science \& Emerging Technologies, 9(4), 495-500 (2008). https://doi.org/10.1016/j. ifset.2008.05.004

USDA - United States Department of Agriculture, Data and Statistics (2017). Retrieved March 3, 2017, from http://www.nass.usda.gov 
